\title{
Two interesting cases of long standing non- asphyxiating intrabronchial foreign bodies
}

\begin{abstract}
The long-standing intrabronchial foreign body presents problems of diagnosis and treatment which are very different from those associated with the recently inhaled foreign body. There may be no history to suggest the original incident; the clinical picture is usually clouded by superadded pathological changes-atelectasis, pneumonitis, or bronchiectasis. Two such cases are presented in an attempt to find common characteristics, recognition of which may assist correct diagnosis. The tracheobronchial foreign bodies are best managed by rigid bronchoscopy. Preventative educational strategies should be implemented to reduce such an avoidable risk.
\end{abstract}

Keywords: bronchoscopy, foreign body, tracheobronchial aspiration
Volume 10 Issue 6 - 2018

\author{
Neha Shakrawa \\ SMS Medical College Jaipur, India
}

Correspondence: Neha Shakrawa, SMS Medical College Jaipur, I80, CBI Colony, Arvind Nagar, Jagatpura, India, Tel 9983552624, Emaildrnehasmnc@gmail.com

Received: September 15, 2017 | Published: November 23, 2018

\section{Introduction}

Foreign body aspiration (FBA) is a dramatic event with serious and potentially lethal sequelae. In 1897, Killian $^{1}$ reported the first case of bronchoscopic removal of a bony foreign body. Later, contributions were made by Jackson and others ${ }^{2-7}$ concerning non-asphyxiating tracheobronchial foreign bodies.

It has been reported that about $50 \%$ of the patients with foreignbody aspiration do not have any relevant history and $20 \%$ of children have undergone medical treatment for other diagnoses for more than 1 month before diagnosis. ${ }^{8}$

In many children, an early diagnosis of FBA is not made. ${ }^{9}$ The problem, to which Jackson ${ }^{10}$ referred as the overlooked diagnosis, continues to be unsolved. Aspirated foreign bodies are responsible for a significant amount of morbidity and mortality in children. Delayed diagnosis of FBA is associated with increased incidence of complications. ${ }^{11-13}$

Mu et al., ${ }^{11}$ in their study have reported a complication rate of $64 \%$, when diagnosis of FBA was made within 47 days and $95 \%$ in the cases of delayed diagnosis of more than 30 days. To prevent complications and death due to FBA, it is vital to diagnose and remove foreign material promptly.

Most aspirated foreign bodies are organic substances; the most prevalent being nuts and beans in children and food pieces and bone in adults. The most common inorganic bodies which are aspirated in children are beads, clips, and small parts of toys and stationery, such as the bottom of pens. ${ }^{8}$

Conventionally, after aspiration, three definite clinical phases occur as follows. The first phase (initial accident) includes acute and severe coughing, choking during eating, gagging, bruising, cyanosis, and probable airway obstruction which immediately follows foreignbody aspiration. In the second phase (asymptomatic phase), the foreign body is settled and immediate simulative symptoms subside. This phase is confusing and causes delay in the patient's referral to a physician by relatives, lack of attention or diagnosis by the physician, and finally lack of suitable treatment. The third phase (complication phase) includes scar, obstruction, or infection which attracts renewed attention to the presence of the foreign body. ${ }^{14}$ In practice, choking attacks and coughing are the most prevalent clinical symptoms. ${ }^{15}$ The presence of sudden choking followed by severe coughing in a child while eating food or playing is a specific and very important indication of the probability of foreign-body aspiration. Foreign-body aspiration should be always considered in children with elongated or abnormal pulmonary symptoms. ${ }^{14,16}$

The purpose of this paper is to review the experience of SMS hospital, Jaipur with 2 unusual cases of retained foreign bodies in the air passages, to discuss the complications and outcomes of children with FBA in late diagnosis, and to examine the reasons of delay in diagnosis.

\section{Illustrative case histories}

Case 1: An 18 girl aged 18 gave a history of 13 years of cough, which had recently become more troublesome with mucopurulent sputum. She had been attending a rural health center for the cough for several years. Radiographs were normal initially. Subs X Rays showed obstructive emphysema on the left side. She remembered swallowing a whistle when she was much younger (around 5 years of age). Before the diagnostic bronchoscopy, a computed tomography (CT) was performed that revealed a soft tissue density in the left main bronchus (Figure 1). Rigid bronchoscopy performed a plastic whistle successfully Retrieval was by under general anesthesia. (Figure 2) There was considerable granulation tissue around the FB.
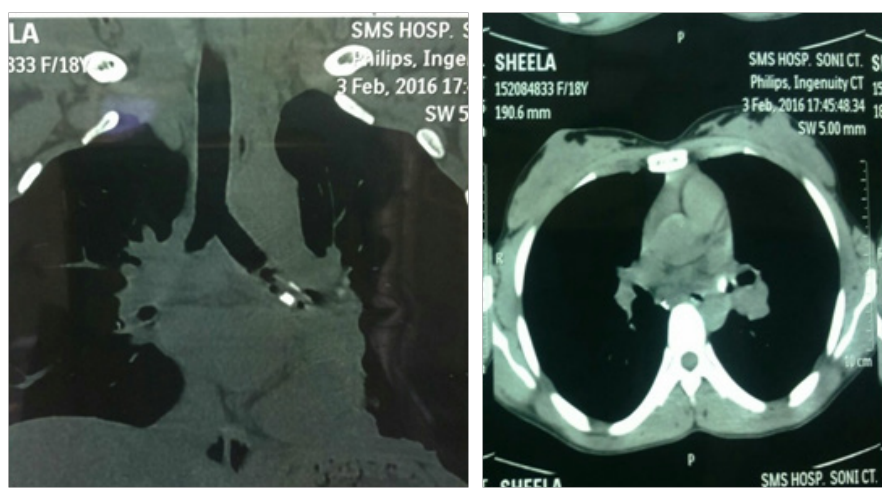

Figure I CT Thorax (coronal and axial slice) showing soft tissue density in left main bronchus. 


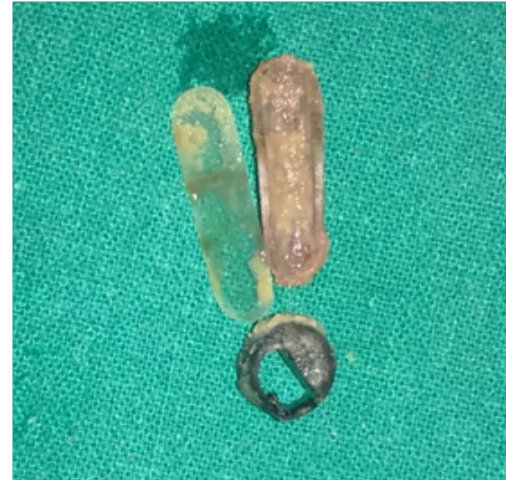

Figure 2 Whistle and its components.

Case 2: A 5 year old girl reported to the hospital with history of chronic cough since 2 years; she had episodes of recurrent URTI. There was no history of FBA. She had been treated many times by physicians for acute bronchitis in this period and experienced temporary relief after medication. She had diminished chest movement on the right and dullness to percussion was elicited on the right as well. She had a markedly diminished breath sound over the right lung field. Chest $\mathrm{X}$ ray was advised which showed a radiopaque object lodged in the right main bronchus with resultant atelectasis of the entire left lung and compensatory emphysema of the right lung (Figure 1) Bronchoscopy revealed a black metallic stud in the right main bronchus. a mass of granulation tissue surrounded the body (Figure 3) (Figure 4) (Figure $5)$.

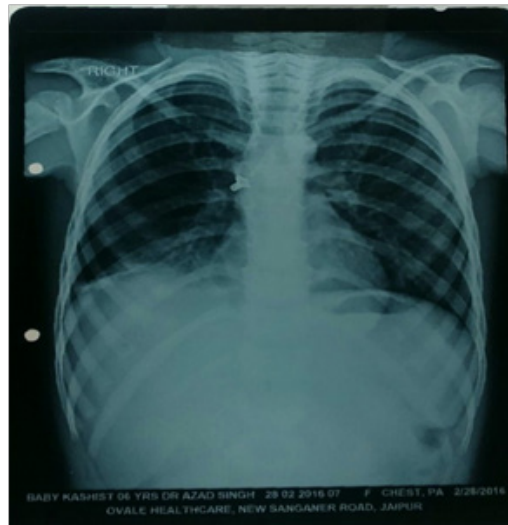

Figure 3 Preoperative chest $\mathrm{x}$-ray films showing metal stud in the right main bronchus.

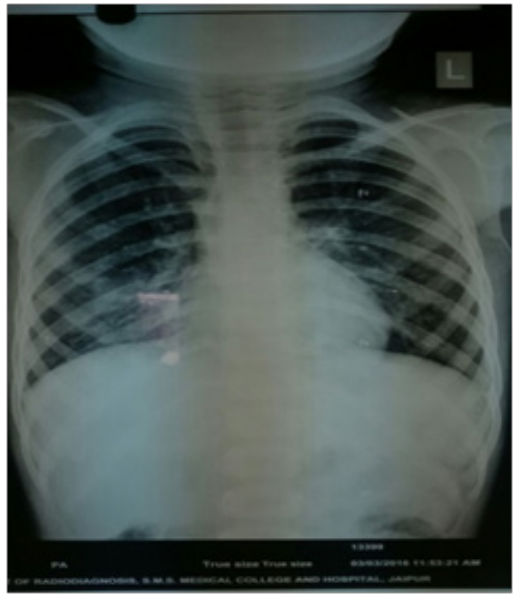

Figure 4 Postoperative Posteranterior chest x- ray.

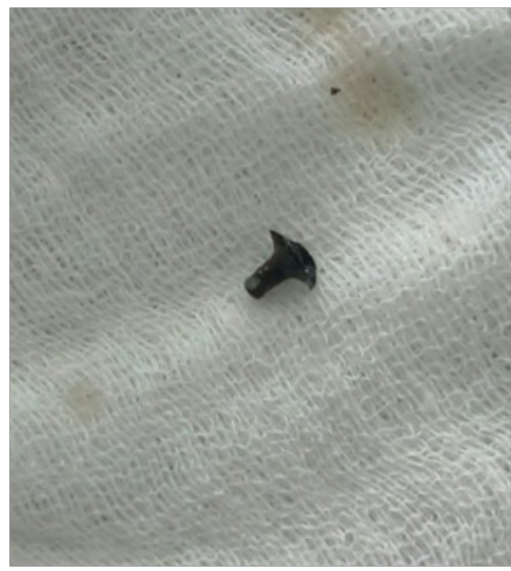

Figure 5 Metal stud retrieved.

\section{Discussion}

Foreign body aspiration is one of the major causes of persistent respiratory symptoms in children, yet is commonly missed by physicians. Early diagnosis and removal of foreign bodies must be achieved to avoid complications.

Diagnosis of foreign body in the airways is still a challenge for the physicians. Only bronchoscopy gives certainty about the diagnosis. ${ }^{17}$

What makes the cases unusual is the delayed and innocuous presentation after aspiration. Case 1 has a history of plastic foreign body ingestion 13 years back. It emphasizes the fact that foreign-body aspiration can be tolerated and remain undetected for a long time. Case 2 has no recollection of consuming peanuts or asphyxiating episode. Both our patient presented after suffering from chronic cough. This delayed presentation can be attributable to larger airways which only become irritated once the aspirated particle becomes dislodged in the peripheral airways or when the bronchial inflammation developed. Thus, the lack of specificity in clinical features resulted in a delay in diagnosis.

A witnessed episode of choking is considered to be an important component of the history that leads to the correct diagnosis of aspiration. A history of choking episode can usually be obtained from parents or caretaker. The absence of choking episode does not rule out FBA and may be a risk factor for diagnostic delay. ${ }^{18}$

The clinical symptoms and signs of FBA depend on type, location, and size of the foreign body, as well as on the duration and the degree of obstruction. ${ }^{19}$ The typical clinical trial of wheezing, coughing and decreased air entry was reported in our patients.

Radiographic examination is an invaluable asset in the diagnosis of an aspirated foreign body. ${ }^{20-22}$ In a radioopaque foreign body, examination is straightforward; when the foreign body is nonradiopaque, secondary changes such as atelectasis and obstructive emphysema are of diagnostic importance. The common radiological sign in our series was obstructive emphysema. A CT thorax is not frequently requested but this is indicated if there is high index of suspicion regarding chronic pulmonary changes due to the prolonged presence of $\mathrm{FB}^{23}$

In our series, late presentation was due to physician misdiagnosis and to a great extent due to parent's negligence. To avoid misdiagnosis, one should be aware that FBA in one of the differential diagnosis in children with symptoms of respiratory tract infection and asthma. 
The morbidities and complications related to FBA and bronchoscopy were more in children who presented late. When dealing with longer-standing organic foreign bodies that induce formation of granulation tissue, Late presentation also endured longer hospitalisation as well as bronchoscopy related laryngeal oedema, bronchospasm, and pneumonia. ${ }^{24-26}$

Early bronchoscopy is essential to reduce the morbidity associated with the complications of prolonged foreign body retention. Rigid bronchoscopy under general anaesthesia is regarded as the procedure of choice for the removal of aspirated foreign bodies. ${ }^{19,24,25}$

\section{Conclusion}

Diagnosis of FBA in children is still a challenge for physicians. Delay in diagnosis appears to result from a failure to give serious consideration to the diagnosis. Medical history is the key for the diagnosis of FBA. Choking and cough are the most common presentations of FBA. Most complications arise due to delayed diagnosis. Physicians taking care of children should be alerted to the importance of history taking in the diagnosis of FBA. They should exercise a high index of suspicion in cases presenting with choking or coughing of sudden onset. Normal appearance of chest Xray does not exclude the possibility of FBA. Early diagnosis and removal of foreign bodies must be achieved to avoid complications. Early bronchoscopy is essential to reduce the morbidity associated with the complications of prolonged foreign body retention.

\section{Acknowledgments}

None.

\section{Conflict of interest}

The author declares there is no conflict of interest.

\section{References}

1. KG. Removal of a bone splinter from the right main bronchus by direct laryngoscopy. Munch Med Wsch. 1897;44:86.

2. JC. Observations on the pathology of foreign bodies in the air and food passages, based on the analysis of 628 cases. Surg Gynecol Obstet. 1919;28:201-261.

3. CL J. Bones as overlooked foreign bodies in the lung. Arch Otolaryngol. 1930;12:499-507.

4. Ann NC. Foreign bodies in the air and food Bronchial Foreign Bodies 513 passages: a series of two hundred and fifty cases. Ann Otol Rhinol Laryngol. 1948;57:1049-1071.

5. Cooley JC, Ginsberg RL, Olsen AM, et al. Foreignbody bronchiectasis. $J$ Thorac Surg. 1956;31(5):615-617.

6. Linton JS. Long-standing intrabronchial foreign bodies. Thorax. 1957;12:164-170.

7. Brooks JW. Foreign bodies in the air and food passages. Ann Surg. 1972;175(5):720-732.

8. Dikensoy O, Usalan C, Filiz A. Foreign body aspiration: clinical utility of flexible bronchoscopy. Postgrad Med J. 2002;78(921):399-403.

9. McGuirt WF, Holmes KD, Feehs R, et al. Tracheobronchial foreign bodies. Laryngoscope. 1988;98(6 Pt 1):615-618.

10. JC. Bronchooesophagology. Philadelphia: W.B. Saunders, 1950, p. 1534
11. Liancai Mu, Ping He, Deqiang Sun. The causes and complications of late diagnosis of foreign body aspiration in children. Arch Otolaryngol Head Neck Surg. 1991;117(8):876-879.

12. Schmidt H, Manegold BC. Foreign body aspiration in children. Surg Endosc. 2000;14(7):644-648.

13. Karakoc F, Karadag B, Akbenlioglu C, et al. Foreign body aspiration: What is the outcome? Pediatr Pulmonol. 2002;34(1):30-36.

14. Mohammad F, Homan H, Zahra AR. Clinical and radiographic findings of foreign body aspiration in children hospitalized in 17 Shahrivar Hospital, Rasht, during 1996-2008. Feiz Journal. 2013;17(5):495-500.

15. Cataneo AJ, Cataneo DC, Ruiz RL. Management of tracheobronchial foreign body in children. Pediatr Surg Int. 2008;24(2):151-156.

16. Sirmali M, Turut H, Kisacik E, et al. The Relationship between Time of Admittance and Complications in Paediatric Tracheobronchial Foreign Body Aspiration. Acta Chir Bel. 20005;105(6):631-634.

17. Yadav SP, Singh J, Aggarwal N. Airway foreign bodies in children: Experience of 132 cases. Singapore Med J. 2007;48(9):850-853.

18. Maren T, Andreas CG, Sergio Stocker, et al. Tracheobronchial foreign body aspiration in childrendiagnostic value of symptoms and signs. Swiss Med Wkly. 2006;136:533-538.

19. Rovin JD, Rodgers BM. Pediatric foreign body aspiration. Pediatr Rev. 2000;21(3):86-90.

20. Brown BS, MAH Dunbar JS, Macewan Dw. Foreign bodies in the tracheobronchial tree in childhood. J Can Assoc Radiol. 1963;14:158171.

21. Daniel CB, Emanual MP, Russelllang R. Foreign bodies in the tracheo-bronchial tree causing obstructive emphysema. Laryngoscope. 1963;3:1099-1105.

22. LJ, FE. Foreign bodies in the bronchial tree and esophagus. Surg Clin N Am. 1966;46:1501-1512.

23. Sersar SI, Rizk WH, Bilal M, et al. Inhaled Foreign Bodies: Presentation, Management and Value of History and Plain Chest Radiography in Delayed Presentation. Otolaryngol Head Neck Surg. 2004;134(1):92-99.

24. Midulla F, Guidi R, Barbato A, et al. Foreign body aspiration in children. Pediatr Int. 2005;47(6):663-668.

25. Hasdiraz L, Oguzkaya F, Bilgin M, et al. Complications of bronchoscopy for foreign body removal: Experience in 1,035 cases. Ann Saudi Med. 2006;26:283-287.

26. Mantor PC, Tuggle DW, Tunell WP. An appropriate negative bronchoscopy rate in suspected foreign body aspiration. Am J Surg. 1989;158(6):6224.

27. Yadav SP, Singh J, Aggarwal N, et al. Airway foreign bodies in children: Experience of 132 cases. Singapore Med J. 2007;48(9):850-853.

28. Cotton E, Yasuda K. Foreign body aspiration. Pediatr Clin North Am. 1984;31(4):937-941.

29. Black RE, Johnson DG, Matlak ME. Bronchoscopic removal of aspirated foreign bodies in children. J Pediatr Surg. 1994;29(5):6824.

30. Cataneo AJ, Cataneo DC, Ruiz RL. Management of tracheobronchial foreign body in children. Pediatr Surg Int. 2008;24:1516.

31. Moore BP. Bronchiectasis with unsuspected foreign body. Br Med J 1952;2(4742):1259-1260.

32. Glennie JS, Dark JF, Lindars DC. Unsuspected foreign body in putrid bronchiectasis. B Med J. 1952;1(4766):1009. 